\title{
Ceramide selectively inhibits apoptosis-associated events in NGF-deprived sympathetic neurons
}

\author{
P Nair ${ }^{1,2}$, SP Tammariello ${ }^{1}$ and S Estus ${ }^{*, 1}$ \\ ${ }^{1}$ Department of Physiology, Sanders-Brown Center on Aging, University of \\ Kentucky, Lexington, Kentucky, KY 40536, USA \\ ${ }^{2}$ Current address: Department of Surgery, UTHSC at San Antonio, 7703 Floyd \\ Curl Drive, San Antonio, Texas, TX 78284, USA \\ * Corresponding author: S Estus; Tel: (606) 323-3985; Fax: (606) 323-2866; \\ E-mail: sestus@aging.coa.uky.edu
}

Received 14.7.99; revised 16.10.99; accepted 25.10.99

Edited by R Lockshin

\begin{abstract}
Ceramide manifests both neurotoxic and neuroprotective properties depending on the experimental system. Ito and Horigome previously reported that ceramide delays apoptosis in a classic model of developmental programmed cell death, i.e. sympathetic neurons undergoing NGF deprivation. ${ }^{1}$ Here, we investigated the actions of ceramide upon the biochemical and genetic changes that occur in NGF deprived neurons. We correlate ceramide's neuroprotective actions with the ability of ceramide to antagonize NGF deprivation-induced oxidative stress and c-jun induction, both of which contribute to apoptosis in this model. However, ceramide did not block NGF deprivation-induced declines in RNA and protein synthesis, suggesting that ceramide does not slow all apoptosis-related events. Overall, these results are significant in that they show that ceramide acts early in the death cascade to antagonize two events necessary for NGF-deprivation induced neuronal apoptosis. Moreover, these results dissociate declines in neuronal function, i.e. macromolecular synthesis, from the neuronal death cascade. Cell Death and Differentiation (2000) 7 , 207-214.
\end{abstract}

Keywords: neuronal apoptosis; c-jun; oxidative stress

Abbreviations: CAPK, ceramide activated protein kinase; CAPP, ceramide-activated protein phosphatase; DCF, 2', 7'-dichlorofluoroscein; DCFDA, 2', 7'-dichlorofluoroscein diacetate; $\mathrm{H}_{2}$ DCFDA, 2', 7'-dichlorodihydrofluoroscein diacetate; TBS, Tris buffered saline

\section{Introduction}

Interest in the actions of ceramide as a modulator of apoptosis has grown dramatically in recent years. ${ }^{2-4}$ Ceramide is reported to modulate apoptosis via several kinase pathways, including MAP kinase, PI-3/AKT kinase, and Jun kinase. ${ }^{5-9}$ Consistent with the pro-apoptotic role of these pathways in some cell types, ceramide is often considered pro-apoptotic. However, ceramide also delays apoptosis in primary cultures of sympathetic neurons undergoing NGF deprivation in vitro. ${ }^{1}$ Similarly, ceramide inhibits apoptosis in other neuronal types or in response to other insults. For example, ceramide also protects sensory neurons from NGF deprivation ${ }^{10}$ and hippocampal neurons from excitotoxic and oxidative insults. ${ }^{11}$ The mechanism(s) underlying the neuroprotective actions of ceramide have not been elucidated.

Many of the morphologic and molecular events that accompany NGF deprivation in sympathetic neurons have been identified. Although few morphologic changes are observed in the first $12 \mathrm{~h}$, the activity of NGF-activated kinases including MAP kinases and PI-3 kinase decreases sharply within 30 min of deprivation. ${ }^{12,13}$ This is followed by an interval of oxidative stress at approximately $4 \mathrm{~h}^{14,15}$ and concomitant declines in total RNA and protein synthesis. ${ }^{16,17}$ As RNA and protein synthesis declines, several genes are selectively induced, including members of the cjun and c-fos families. ${ }^{18,19}$ Members of the caspase family are then activated leading to degradation of genomic DNA into nucleosomal fragments at approximately $19 \mathrm{~h}^{16,17,20}$ Neuronal death as assessed by staining with vital dyes begins $\sim 24 \mathrm{~h}$ after deprivation and is largely complete by $48 \mathrm{~h}$. The apoptotic role of several of these events has been elucidated. Inhibitors of oxidative stress and c-Jun at least delay apoptosis ${ }^{14,18,19}$ while caspase inhibitors block apoptosis essentially indefinitely. ${ }^{20}$ In summary, to gain insight into ceramide's ability to delay apoptosis, we evaluated the actions of ceramide on several of these molecular events. Here, we report that ceramide inhibits oxidative stress and c-jun induction, without altering declines in RNA or protein synthesis or activating the MAP kinase pathway. These results suggest novel roles for ceramide in delaying neuronal death.

\section{Results}

\section{Ceramide antagonizes NGF deprivation-induced sympathetic neuron death}

To begin to evaluate ceramide actions, we confirmed that ceramide antagonizes apoptosis in NGF-deprived sympathetic neurons, as reported by others. ${ }^{1}$ Neurons were deprived of NGF and simultaneously treated with ceramide or DMSO vehicle. Apoptosis was visualized as chromatin condensation $24 \mathrm{~h}$ later by using Hoechst 33258 staining and fluorescent microscopy. ${ }^{16,17}$ As expected, NGF deprivation increased the frequency of neurons manifesting chromatin condensation (Figure 1B) relative to NGF maintained neurons (Figure 1A). In contrast to its pro-apoptotic effects in many cell types, ceramide did not induce chromatin condensation in the presence of NGF (Figure 1C). Indeed, ceramide reduced the frequency of such neurons in NGF deprived cultures (Figure 
1D). The biologically 'inactive' analog of ceramide, dihydroceramide, had no effect on NGF deprivation (Figure 1E). Quantitation of these effects established that ceramide but not dihydroceramide was neuroprotective (Figure 1F $(P<0.05)$ ). This neuroprotection was not as complete as that observed for protein synthesis inhibitors such as cycloheximide ${ }^{21}$ or caspase inhibitors, ${ }^{20,21}$ as $\sim 8 \%$ of neurons still underwent apoptosis in the presence of ceramide. Indeed, we observed that the neuroprotective actions of ceramide were eventually overcome with increasing duration of NGF deprivation; as reported by Ito and Horigome, ${ }^{1}$ the neurons underwent apoptosis beginning some $48-72 \mathrm{~h}$ after NGF deprivation (data not shown, for quantitation, see ${ }^{1}$ ). In summary, in sharp contrast to the pro-apoptotic actions of ceramide in many situations, $^{2-4}$ ceramide antagonizes apoptosis in NGF deprived sympathetic neurons.

\section{Ceramide antagonizes 'apoptosis-associated' gene expression}

Since we and others previously reported that c-Jun is induced during and is necessary for apoptosis caused by NGF deprivation, ${ }^{18,19}$ we began evaluating the actions of ceramide by examining patterns of apoptosis-associated gene expression. We compared the temporal patterns of expression of four 'baseline' genes and three 'apoptosis-associated' genes. The baseline genes included actin and cyclophilin, which are expressed constitutively in all cell types, and NSE and $\mathrm{TOH}$, which are neuron-specific. The relative invariability of the baseline genes early in the time course of deprivation demonstrates the uniformity of neuronal plating. The decline in these genes with NGF deprivation reflects differences in neuronal death, e.g. TOH and NSE decline more slowly in the presence of ceramide (Figure 2A). NGF deprivation led to robust c-jun, c-fos, and fosB inductions (Figure 2). ${ }^{18,19}$ Ceramide delayed and decreased each gene induction (Figure 2). For example, ceramide decreased the maximal c-jun induction to 50 and $62 \%$ of that of neurons undergoing NGF deprivation per se (two independent neuronal preparations). Ceramide also delayed and decreased the induction of $\mathrm{c}$-fos and $f \circ s B$, actions which likely reflect that ceramide delays apoptosis because in situ hybridization studies have shown that at least c-fos is induced coincident with chromatin condensation. ${ }^{18}$ In summary, ceramide inhibited the induction of apoptosis-related genes, including that of $c$-jun, which encodes a protein necessary for death in this model. ${ }^{18,19}$

\section{Ceramide blocks NGF deprivation-induced oxidative stress}

Oxidative stress is a result of NGF deprivation, activates cJun, and is necessary for apoptosis. ${ }^{14,18,19,22,23}$ Since ceramide inhibited c-jun induction, we hypothesized that ceramide may modulate oxidative stress. Hence, we evaluated ceramide effects on oxidative stress, which is a transient event, occurring 3-4 h after NGF deprivation. ${ }^{14}$ Oxidative stress was quantified by using $\mathrm{H}_{2}$ DCFDA, which is converted to fluorescent DCF upon oxidation and cleavage of its acetate groups by cellular esterases. Neurons were exposed to ceramide or DMSO vehicle in the presence or absence of NGF for $3.5 \mathrm{~h}$, loaded with $\mathrm{H}_{2}$ DCFDA for 30 min, and DCF fluorescence quantified. NGF deprivation induced a
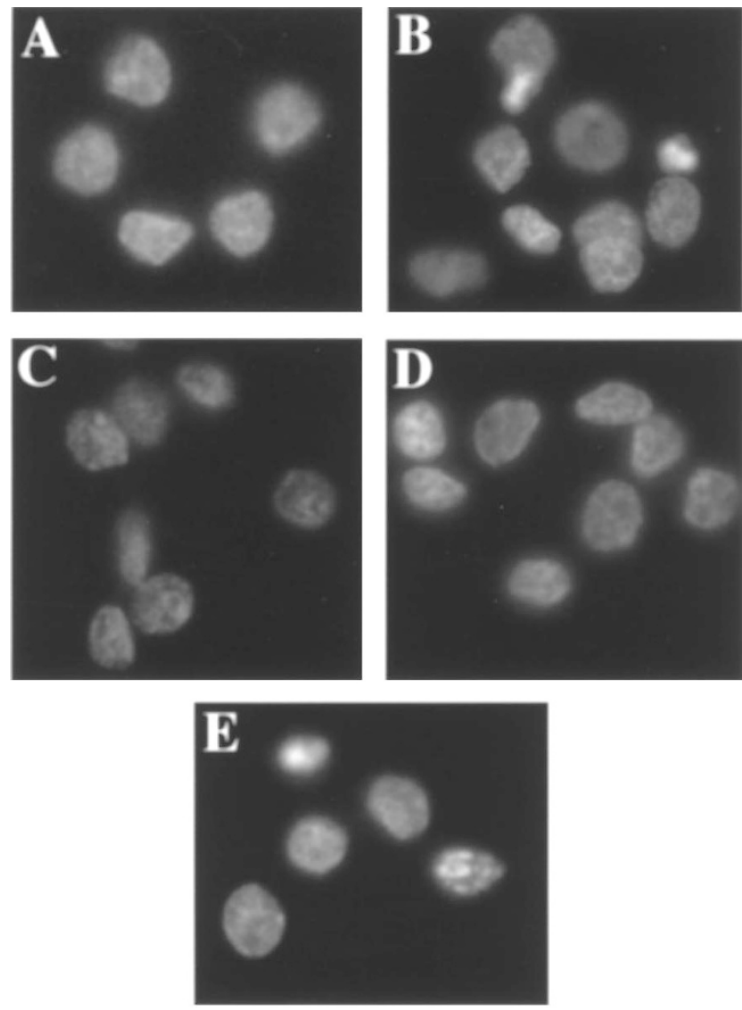

\section{F}

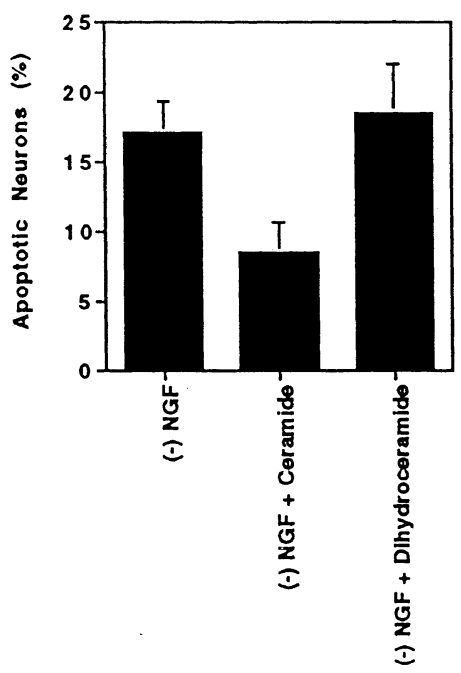

Figure 1 Ceramide inhibits NGF deprivation induced chromatin condensation. These fluorescent microscopy images depict Hoechst 33258-stained neurons maintained with NGF (A), deprived of NGF for $24 \mathrm{~h}(\mathbf{B})$, maintained with NGF in the presence of ceramide (C), or deprived of NGF in the presence of ceramide (D) or dihydroceramide (E). That ceramide, but not dihydroceramide, decreases the frequency of chromatin condensation, as established by counts of neurons manifesting condensed chromatin, is shown in $\mathbf{F}(P<0.05$, ANOVA analysis with post hoc Fishers PLSD). Original magnification of photomicrographs was $400 \times$ 
A.

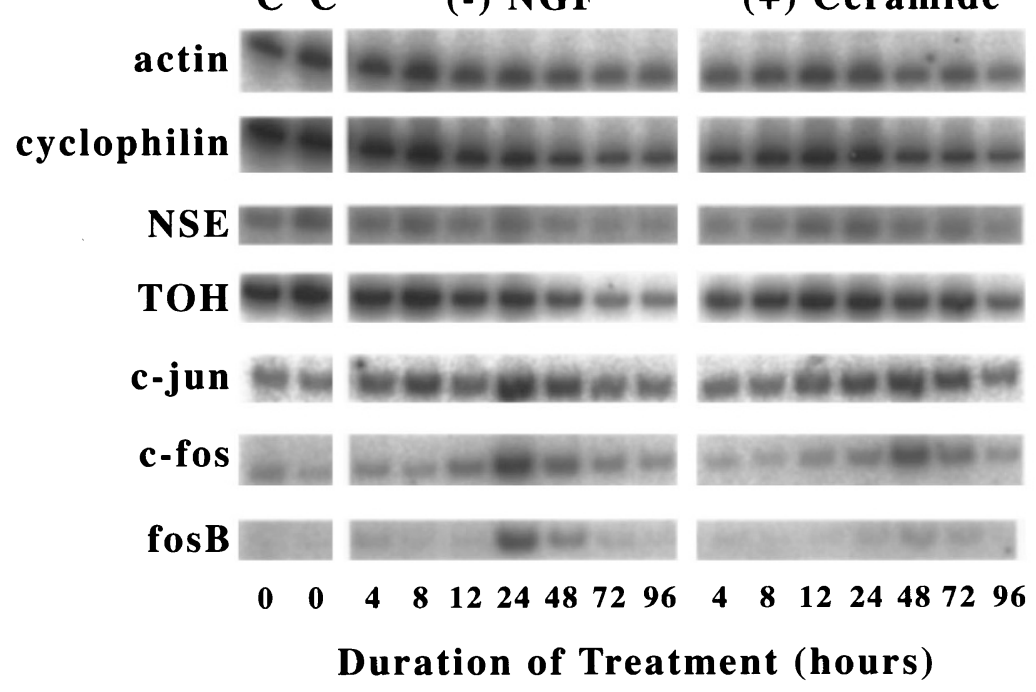

B.

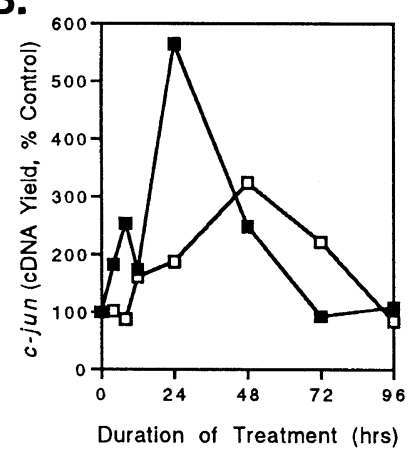

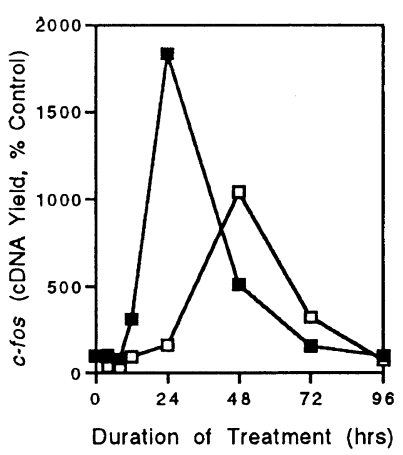

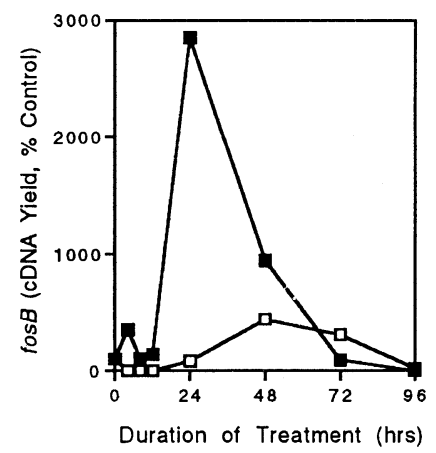

$\longrightarrow-(-)$ NGF $\quad \longrightarrow-(\cdot) \mathrm{NGF}(+)$ Ceramide

Figure 2 Ceramide delays apoptotic pattern of gene expression. Neuronal cultures were deprived of NGF in the presence or absence of ceramide. Changes in gene expression were analyzed by quantitative RT-PCR in poly-A+RNA isolated at the indicated intervals. The results of several reference genes, as well as genes implicated in apoptosis are depicted (A) and changes in selected genes are quantified (B). Similar results were obtained in two separate neuronal preparations

significant, twofold increase in DCF fluorescence (Figure 3A), confirming the work of others. ${ }^{14}$ Ceramide significantly decreased DCF fluorescence induced by NGF deprivation $(P<0.05)$ and had no effect on NGF maintained neurons (Figure 3A). Since DCF fluorescence can be altered artifactually, ${ }^{24}$ we evaluated ceramide effects on cells loaded with DCFDA, which is converted directly to DCF by cytosolic esterases, independent of oxidative stress. Neither ceramide nor NGF deprivation altered the fluorescence of neurons loaded with DCFDA (Figure 3B). In summary, these results indicate that ceramide decreases the oxidative stress induced by NGF deprivation. This effect may explain ceramide's ability to antagonize apoptosis because oxidative stress is necessary for death. ${ }^{14,25}$ Moreover, since oxidative stress likely contributes to c-jun induction in NGF deprived neurons, ${ }^{26}$ the ability of ceramide to inhibit oxidative stress may be upstream of its actions on c-jun.

\section{The MAP kinase pathway is not activated by ceramide}

Two lines of evidence suggest that ceramide may modulate oxidative stress by activating the MAP kinase pathway. First, ceramide activates this kinase pathway in some cell types. ${ }^{7}$ Second, adding NGF back to NGF-deprived cultures inhibits oxidative stress via the MAP kinase pathway because the MAP kinase inhibitor PD098059 blocks this NGF action. ${ }^{15}$ Therefore, we examined whether ceramide activates the MAP kinase pathway in sympathetic neurons. To reduce the NGF stimulated level of MAP kinase activity, neurons were deprived of NGF for $14 \mathrm{~h}$, which is insufficient to induce apoptosis. The neurons were then either left unstimulated for $30 \mathrm{~min}$, or were treated with ceramide or NGF for $30 \mathrm{~min}$. Activation of the MAP kinase pathway was assessed by two means. First, ERK activation was assessed by detecting ERK 
A.

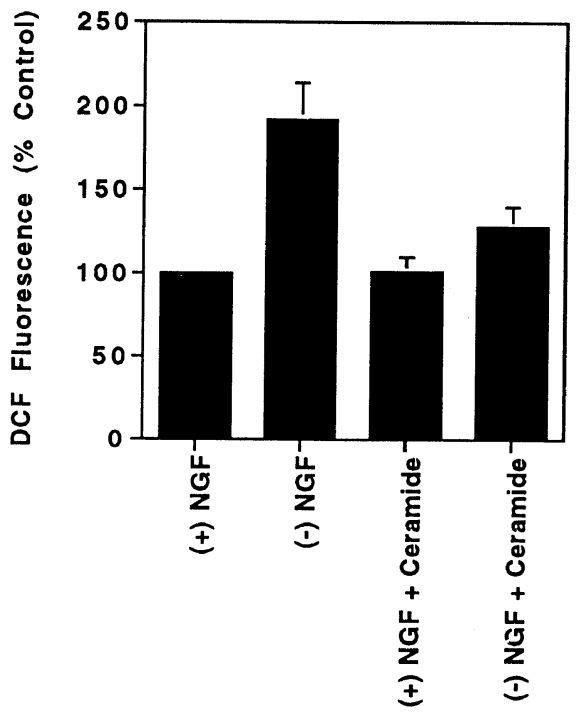

B.

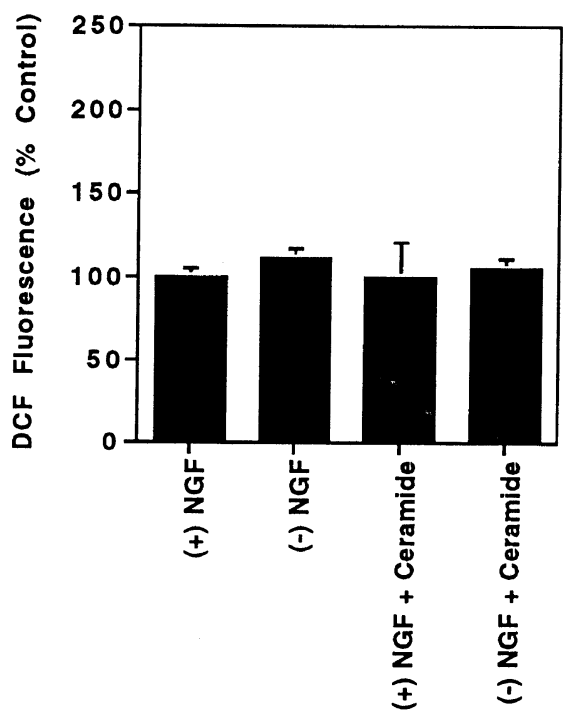

Figure 3 Ceramide inhibits NGF deprivation-induced oxidative stress. Neurons were treated with or without ceramide in the presence or absence of NGF for $3.5 \mathrm{~h}$. The cultures were then loaded with an oxidation-sensitive fluorochrome, i.e. $\mathrm{H}_{2}$ DCFDA (A), or, to assess the possibility of artifactual change in DCF fluorescence, with the fluorochrome DCFDA (B). DCF fluorescence was then measured with a microtiter plate reader. Ceramide inhibited the oxidative stress induced by NGF deprivation $(\mathbf{A})$, and this effect was not the result of an artifactual change in DCF fluorescence $(\mathbf{B})$. The depicted results represent the mean \pm S.E. of three independent neuronal preparations, each analyzed in triplicate $(\mathbf{A})$ or the mean \pm S.D. for a representative set of neurons, analyzed in triplicate (B)

phosphorylation by using a phospho-ERK antibody to label neurons (Figure 4A-C), which were counterstained with Hoechst 33258 to show the presence of neurons (Figure 4D-F). NGF stimulation caused a robust increase in ERK phosphorylation (Figure 4B), relative to the unstimulated cells (Figure 4A). That neurons were present in each case is documented by the Hoechst 33258 staining in parallel (Figure $4 D, E)$. In contrast to this robust NGF effect, ceramide treatment did not increase phospho-ERK labeling (Figure 4C,F).

We also assessed whether ceramide activated the MAP kinase pathway by using Western blots to examine ERK phosphorylation (Figure 4G). NGF again induced a clear increase in ERK phosphorylation (lane 2) while ceramide treated cells (lane 3 ) were similar to unstimulated cells (lane 1). That similar amounts of protein were loaded into each lane was demonstrated by labeling with an antibody against total ERKs. Hence, ceramide does not appear to activate the MAP kinase pathway in sympathetic neurons.

\section{Ceramide does not block NGF deprivation-induced metabolic dormancy}

Since the actions of ceramide might be attributable to an overall slowing in cellular metabolism, we examined the effects of ceramide on macromolecular synthesis. RNA and protein synthesis was quantified by $\left[5,6-{ }^{3} \mathrm{H}\right]$ uridine and $\left[{ }^{35} \mathrm{~S}\right] \mathrm{L}$ methionine incorporation, respectively. NGF deprivation per se caused a profound decline in macromolecular synthesis well before neuronal death (Figure 5), as reported by others. $^{16,17}$ However, ceramide had no effect on this metabolic decline (Figure 5). In the presence of NGF, ceramide showed only a modest and delayed inhibition of
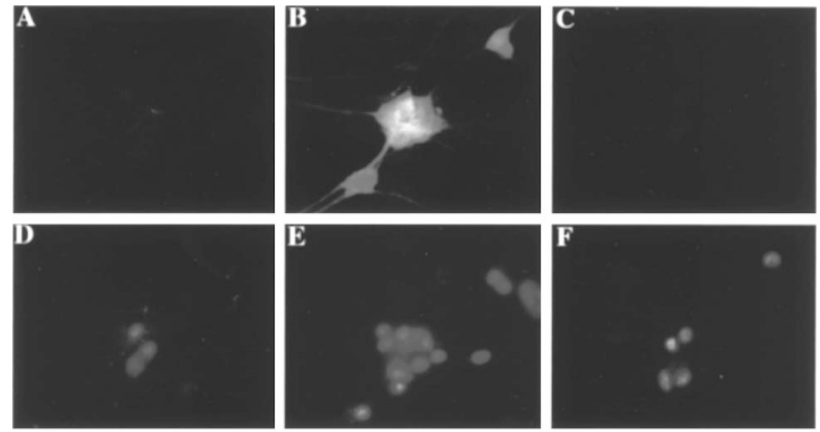

G.

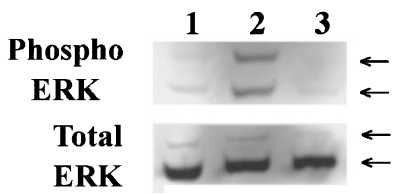

Figure 4 Ceramide does not activate the MAP kinase pathway. MAP kinase activation was assessed by anti-phospho-ERK immunofluorescence $(\mathbf{A}-\mathbf{C})$ in cells that were counterstained with Hoechst 33,258 (D-F) or by Western blots for total and phospho-ERK proteins $(\mathbf{G})$. Sympathetic neurons were deprived of NGF for $14 \mathrm{~h}$ to reduce background activity and then left untreated $(\mathbf{A}, \mathbf{D}, \mathbf{G}$ lane 1) or restimulated with $\mathrm{NGF}(50 \mathrm{ng} / \mathrm{ml})(\mathbf{B}, \mathbf{E}, \mathbf{G}$ lane 2$)$ or ceramide $(\mathbf{C}, \mathbf{F}$, G lane 3). Immunofluorescent photos were exposed and processed identically. Ceramide was also incapable of causing an increase in phospho-ERK immunofluorescence in neurons initially deprived of NGF for only $3 \mathrm{~h}$ (data not shown)

RNA and protein synthesis, as reported by others $\left({ }^{1}\right.$, data not shown). Hence, the apoptosis-delaying actions of ceramide do not involve an exacerbated decline in cellular metabolism. 

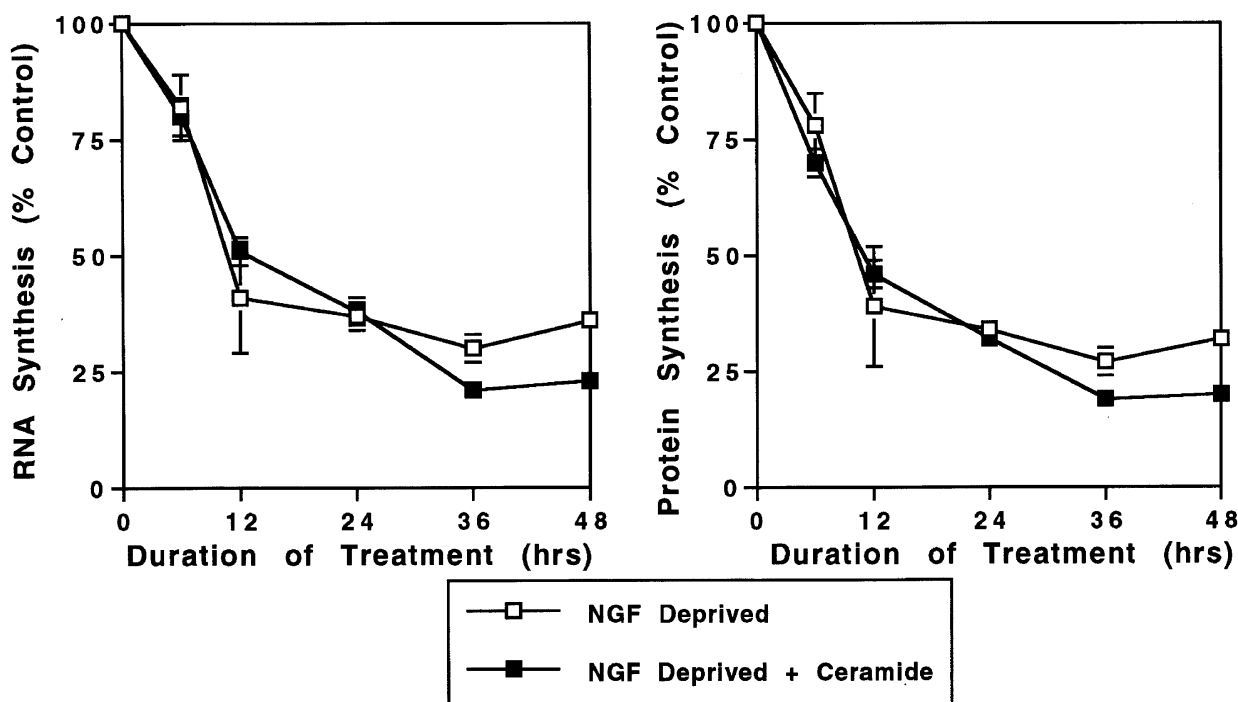

Figure 5 Ceramide does not block NGF deprivation-induced decline in macromolecular synthesis. Neuronal preparations were treated with or without ceramide in the presence or absence of NGF for the indicated intervals. They were then exposed to [35S] L-methionine and [5,6-3H] uridine for $4 \mathrm{~h}$ and incorporated amino acid and uridine quantified by scintillation counting of TCA precipitates. These results represent the mean \pm S.E. of samples treated and analyzed in triplicate. Similar results were obtained in a separate set of neurons analyzed independently

\section{Discussion}

The primary findings reported here are that ceramide selectively antagonizes certain events associated with NGF deprivation-induced apoptosis in sympathetic neurons. More specifically, ceramide antagonized oxidative stress, c-jun induction, and apoptosis, but had no effect on metabolic decline. We interpret these results as suggesting that the currently unknown pathway leading to metabolic dormancy is divergent from the postulated pathway involving oxidative stress, c-jun induction, and apoptosis. Moreover, since ceramide did not activate the MAP kinase pathway, which is the only pathway known to block oxidative stress in this system, ceramide may act via a novel mechanism to block the oxidative stress induced by NGF deprivation. Overall, ceramide is emerging as a second messenger with multipotent actions, the final result of which depend on cell type and cellular environment. Although ceramide is frequently considered as an inducer of apoptosis in non-neuronal cells, our results are in agreement with other reports suggesting that ceramide can inhibit neuronal apoptosis in response to several stimuli. ${ }^{1,10,11}$ Our results contribute to the understanding of ceramide mechanisms by revealing unexpected and possibly cell-type specific actions of ceramide, that is, inhibition of oxidative stress and c-jun induction.

The ability of ceramide to inhibit oxidative stress may account for its ability to antagonize c-jun induction and apoptosis because oxidative stress occurs prior to and is required for c-jun induction and apoptosis. ${ }^{14,23}$ Recently, we reported that the superoxide producing enzyme $\mathrm{NADPH}$ oxidase is present in sympathetic neurons and contributes to their oxidative stress and apoptosis after NGF deprivation. ${ }^{27}$ Hence, one possible target for the antioxidant actions of ceramide is NADPH oxidase. Although the mechanism(s) activating NADPH oxidase and a possible role for ceramide in this pathway are unclear, these two pathways intersect at the point of Rac1. A small GTP-binding protein, Rac1 is activated after NGF deprivation $^{28}$ and is known to maximize NADPH oxidase activation in other cell types. ${ }^{29}$ Rac1 is activated after ceramide treatment in lymphocytic cells. ${ }^{30}$ Hence, ceramide may inhibit oxidative stress via a competition for second messengers that are involved in both pathways. Although the activation of the MAP kinase pathway is required for NGF to suppress reactive oxygen species generation, ${ }^{15}$ this pathway was not activated by ceramide. That ceramide but not dihydroceramide antagonized apoptosis suggests that ceramide acts through one of the three enzymes that have been associated with direct ceramide actions, which include PKC-zeta, ceramide activated protein kinase (CAPK), and ceramide-activated protein phosphatase (CAPP) (reviewed in Mathias et al. ${ }^{4}$ ). Little is known regarding PKC-zeta and apoptosis. While CAPK has been implicated in phosphorylation of the EGF receptor, ${ }^{31}$ ceramide likely does not act via the NGF high affinity receptor Trk in a similar fashion as ceramide did not increase ERK phosphorylation. If oxidative stress is separable from c-jun activation, ceramide-induced CAPP activation may inhibit c-jun induction by inhibiting the JNK pathway, which we and others have shown is activated in NGF-deprived sympathetic neurons. ${ }^{32-34}$ In summary, our observation that ceramide inhibits oxidative stress induced by NGF deprivation, and reports that oxidative stress is sufficient to activate the JNK pathway and c-jun expression $^{22,23}$ suggests the most parsimonious explanation of ceramide actions focuses on the pathways leading to oxidative stress.

Considering the actions of ceramide more generally, the cell cycle may play a role in the ceramide's neuroprotective effects. As part of ceramide's actions as a cellular 'biostat', 
ceramide has been reported to induce cell cycle arrest at the $G_{0} / G_{1}$ boundary in multiple cell types (reviewed $\mathrm{in}^{2}$ ). Since we and other have reported that neurons undergoing apoptosis manifest aspects of cell cycle re-entry, including the induction of genes necessary for cell cycle progression through the $\mathrm{Go} / \mathrm{G}_{1}$ boundary such as cyclinD $1,{ }^{35,36}$ the antiapoptotic effects of ceramide may reflect arrested cell cycle progression. Consistent with this possibility, oxidative stress in some cell types has been shown to contribute to cell proliferation, and indeed may mediate the effects of at least some proliferative agents (reviewed $\mathrm{in}^{37}$ ). Hence, the actions of ceramide in blocking oxidative stress may be relevant to cell cycle re-entry as well.

In summary, neuronal apoptosis has been implicated in chronic neurodegenerative diseases such as Alzheimers disease, ${ }^{38-40}$ and acute conditions such as stroke. ${ }^{41-43}$ Hence, elucidating the neuroprotective mechanisms of agents such as ceramide may lead to therapeutically relevant insights. Here, the demonstration that ceramide antagonizes apoptosis without supporting RNA and protein synthesis suggests that the ceramide-modulated pathways are probably not strong candidate targets for chronic therapy. However, agents such as ceramide that promote neuronal survival in the short-term may lead to useful therapies in acute situations.

\section{Materials and Methods}

\section{Neuronal cultures}

Primary cultures of sympathetic neurons were prepared and maintained with NGF $(50 \mathrm{ng} / \mathrm{ml})$ for $5-7$ days as described previously. ${ }^{18} \mathrm{NGF}$ deprivation was performed by replacing the NGFcontaining medium with an identical medium except that NGF was replaced with an NGF neutralizing antibody (Sigma). C6-ceramide (Cayman Chemicals, Ann Arbor, MI, USA) stock solutions (25 mM) were made in DMSO and then added to the culture dishes to a concentration similar to that shown to be neuroprotective by others, i.e. $12-18 \mu \mathrm{M} ;{ }^{11}$ similar results were obtained with each concentration. Control cultures were treated with DMSO vehicle only.

\section{Cell death assays}

Cultures were exposed to ceramide with or without NGF for $24 \mathrm{~h}$, fixed with $4 \%$ paraformaldehyde in PBS for $20 \mathrm{~min}$, and stained with Hoechst 33258 at a concentration of $1 \mu \mathrm{g} / \mathrm{ml}$ in PBS for $10 \mathrm{~min}$. The frequency of neurons manifesting condensed or punctate chromatin was then scored by an observer 'blinded' as to neuronal treatments. The experiments were performed in triplicate, with at least 250 neurons being scored in each dish. The effects of ceramide were quantified in four independent experiments, with the effects of dihydroceramide being quantified in the last two experiments in parallel. After correction for background neuronal death, i.e. the frequency of death in NGF-maintained dishes, differences in neuronal death were analyzed by ANOVA for an incomplete block design, with a post-hoc Fishers PLSD comparison of the means.

\section{Gene expression assays}

RT-PCR quantitation of gene expression was performed as described previously. ${ }^{18}$ Briefly, poly-A+ RNA isolated from $\sim 1,000$ neurons was converted to cDNA by using random hexamers to prime reverse transcriptase (Superscript II, Life Technologies, Gaithersburg, MD, USA). Stock PCR reaction mixtures $(50 \mu \mathrm{l})$ were prepared on ice and contained $50 \mu \mathrm{M}$ dCTP, $100 \mu \mathrm{M}$ each of dGTP, dATP and dTTP, $10 \mu \mathrm{Ci}\left[{ }^{32} \mathrm{P}\right] \mathrm{dCTP}(3000 \mathrm{Ci} / \mathrm{mmole}), 1 \times$ reaction buffer (Life Technologies), $1 \mu \mathrm{M}$ each primer, $1 \mathrm{U}$ of Taq polymerase (Life Technologies) and $3 \%$ of the cDNA synthesized in the reverse transcription. The stock solutions were then separated into three aliquots that were covered with mineral oil and subjected to various numbers of cycles of PCR. The use of multiple cycles allows us to determine the minimum number of cycles necessary to detect PCR product, and thereby stay within the linear region of PCR amplification. Typical reaction conditions were one min at $94^{\circ} \mathrm{C}, 1 \mathrm{~min}$ at $55^{\circ} \mathrm{C}$ and $2 \mathrm{~min}$ at $72^{\circ} \mathrm{C}$. After amplification, the cDNAs were separated by polyacrylamide gel electrophoresis and visualized by using phosphorimaging technology. The sequences of the primers used were published previously. ${ }^{44,45}$ This assay was validated by showing that PCR product yields were linear with respect to input RNA and that the technique detected known gene inductions in neuronal cultures, i.e. HSP70 in a heat shock paradigm. ${ }^{44}$

\section{Oxidative stress measurements}

Oxidative stress was quantified by using the indicator $2^{\prime}, 7^{\prime}$ dichlorodihydrofluoroscein diacetate $\left(\mathrm{H}_{2} \mathrm{DCFDA}\right.$, Molecular Probes, Eugene, OR, USA) which is converted by oxidative stress and cellular esterases to the fluorescent $2^{\prime}, 7^{\prime}$-dichlorofluoroscein (DCF). We also quantified the effects of ceramide on the fluorescence of cells treated with 2',7'-dichlorofluoroscein diacetate (DCFDA, Molecular Probes), which is an already oxidized version of $\mathrm{H}_{2}$ DCFDA. Neurons were plated onto 96 well tissue culture plates at a density of $\sim 1000$ neurons/well. After $5-6$ days in culture, neurons were either maintained or deprived of NGF, in the presence or absence of ceramide for $3.5 \mathrm{~h} . \mathrm{H}_{2}$ DCFDA or DCFDA was then added to a final concentration of $160 \mu \mathrm{M}$. Samples were treated in triplicate or greater. The dishes were returned to the $37^{\circ} \mathrm{C}$ incubator for $30 \mathrm{~min}$. Fluorescence emission at $535 \mathrm{~nm}$ after excitation at $485 \mathrm{~nm}$ was quantified by using a plate reader (Perkin Elmer HTS-7000). Because of potential oxidation by the excitation laser, samples were scanned only once. Differences between ceramide and untreated samples were analyzed by using a Students $t$-test.

\section{ERK immunofluorescence}

Neurons were deprived of NGF for $14 \mathrm{~h}$ and then retreated with NGF $(50 \mathrm{ng} / \mathrm{ml})$ or with C6-ceramide for $30 \mathrm{~min}$. Cells were fixed with $4 \%$ paraformaldehyde, permeabilized with $0.5 \%$ Triton X-100 in TBS, blocked with antibody buffer (TBS $+5 \%$ goat serum $+0.3 \%$ Triton $X-100$ ) and then labeled overnight with an antibody against phosphorylated MAP kinase (Promega) diluted 1:200 in antibody buffer. After two TBS washes, the cells were exposed to cy-3 conjugated, anti-rabbit secondary antibody (Jackson Immunochemicals) for $2 \mathrm{~h}$. The plates were washed twice with TBS and stained with Hoechst 33,258 (Molecular Probes). Staining was detected with fluorescence microscopy. To standardize the images, film exposure times and subsequent processing procedures were identical among the various samples and images.

\section{Western blotting analysis}

Sympathetic neuronal cultures (20 000 cells/plate) were deprived of NGF for $14 \mathrm{~h}$ and then treated with either NGF or C6-ceramide for 
$30 \mathrm{~min}$. Proteins were electrophoresed on 15\% SDS-PAGE gels, transferred onto PVDF membranes, blocked in 5\% milk, and probed with a total MAP kinase antibody (New England Biolabs; 1:1000 dilution) or a phospho-MAP kinase antibody (Promega; 1:20000 dilution) overnight. The membranes were washed with $0.1 \%$ Tween in TBS, labeled with HRP-conjugated anti-rabbit secondary antibodies (Amersham, 1:2000 dilution) for $2 \mathrm{~h}$ and then washed again in $0.1 \%$ Tween in TBS. Labeled proteins were detected by using ECL-PLUS (Amersham).

\section{Metabolic parameters}

RNA and protein synthesis rates were determined by using a protocol described by others. ${ }^{16}$ Neuronal cultures were maintained in 24 -well plates (approximately 2500 cells/well). The culture medium was then replaced with medium containing $10 \mu \mathrm{M} \mathrm{L}$-methionine, with or without NGF and/or ceramide or DMSO vehicle. Parallel cultures that were NGF deprived upon neuronal plating, and therefore consisting only of non-neuronal cells, were used to provide background values. At the indicated times, cultures were exposed to $10 \mu \mathrm{Ci} / \mathrm{ml}\left[{ }^{35} \mathrm{~S}\right] \mathrm{L}$-methionine (>1000 Ci/mmol) and $10 \mu \mathrm{Ci} / \mathrm{ml}\left[5,6-{ }^{3} \mathrm{H}\right]$ uridine $(35-50 \mathrm{Ci} / \mathrm{mmol})$ for $4 \mathrm{~h}$ at $37^{\circ} \mathrm{C}$. The cells were washed with medium and lysed with $500 \mu \mathrm{l}$ buffer containing $0.5 \%$ SDS, $1 \mathrm{mM}$ EDTA, and $10 \mathrm{mM}$ Tris ( $\mathrm{pH} 7.5)$. Ten $\mu \mathrm{g}$ each of BSA and yeast tRNA were added to each sample and the protein and RNA precipitated simultaneously by adding cold $10 \%$ trichloroacetic acid and $1 \%$ sodium pyrophosphate on ice. Precipitates were captured on a $0.45 \mu \mathrm{m}$ nitrocellulose filter, washed with cold $10 \%$ TCA, water, and finally with $70 \%$ ethanol. The filters were dried and radioactivity quantified by liquid scintillation counting. Radioactivity in each sample was normalized by subtracting the radioactivity in the background sample and then dividing by the average c.p.m. observed in parallel culture samples maintained in NGF. In preliminary work, we demonstrated that radioactivity incorporation was linear with respect to labeling time for at least $4 \mathrm{~h}$ (data not shown).

\section{Acknowledgements}

The authors would like to acknowledge the support of NIH (S Estus, grant NS-34370 and SP Tammariello, AG-00242) and HM Tucker, for critical discussions of the manuscript and for preparing the figures. We also acknowledge R Kyruscio for statistical analysis and JP McGillis for critical comments on the manuscript.

\section{References}

1. Ito A and Horigome K (1995) Ceramide prevents neuronal programmed cell death induced by nerve growth factor deprivation. J. Neurochem. 65: 463-466

2. Hannun YA (1996) Functions of ceramide in coordinating cellular responses to stress. Science 274: 1855-1859

3. Haimovitz-Friedman A, Kolesnick RN and Fuks Z (1997) Ceramide signaling in apoptosis. Br. Med. Bull. 53: 539-553

4. Mathias S, Pena LA and Kolesnick RN (1998) Signal transduction of stress via ceramide. Biochem. J. 335: 465-480

5. Raines MA, Kolesnick RN and Golde DW (1993) Sphingomyelinase and ceramide activate mitogen-activated protein kinase in myeloid HL-60 cells. J. Biol. Chem. 268: 14572-14575

6. Westwick JK, Bielawska AE, Dbaibo G, Hannun YA and Brenner DA (1995) Ceramide activates the stress-activated protein kinases. J. Biol. Chem. 270: 22689-22692

7. Yao B, Zhang Y, Delikat S, Mathias S, Basu S and Kolesnick R (1995) Phosphorylation of Raf by ceramide-activated protein kinase. Nature 378: 307 310
8. Verheij M, Bose R, Lin XH, Yao B, Jarvis WD, Grant S, Birrer MJ, Szabo E, Zon LI, Kyriakis JM, Haimovitz-Friedman A, Fuks Z and Kolesnick RN (1996) Requirement for ceramide-initiated SAPK/JNK signalling in stress-induced apoptosis. Nature 380: 75-79

9. Gulbins E, Brenner B, Koppenhoefer U, Linderkamp O and Lang F (1998) Fas or ceramide induce apoptosis by Ras-regulated phosphoinositide-3-kinase activation. J. Leukoc. Biol. 63: 253-263

10. Ping SE and Barrett GL (1998) Ceramide can induce cell death in sensory neurons, whereas ceramide analogues and sphingosine promote survival. J. Neurosci. Res. 54: 206-213

11. Goodman Y and Mattson MP (1996) Ceramide protects hippocampal neurons against excitotoxic and oxidative insults, and amyloid beta-peptide toxicity. J. Neurochem. 66: 869-872

12. Creedon DJ, Johnson EM and Lawrence JC (1996) Mitogen-activated protein kinase-independent pathways mediate the effects of nerve growth factor and cAMP on neuronal survival. J. Biol. Chem. 271: 20713-20718

13. Crowder RJ and Freeman RS (1998) Phosphatidylinositol 3-kinase and Akt protein kinase are necessary and sufficient for the survival of nerve growth factordependent sympathetic neurons. J. Neurosci. 18: 2933-2943

14. Greenlund LJS, Deckwerth TL and Johnson EM (1995) Superoxide dismutase delays neuronal apoptosis: a role for reactive oxygen species in programmed neuronal death of protects sympathetic neurons from NGF deprivation induced apoptosis. Neuron 14: 303-315

15. Dugan LL, Creedon DJ, Johnson EM and Holtzman DM (1997) Rapid suppression of free radical formation by nerve growth factor involves the mitogen-activated protein kinase pathway. Proc. Natl. Acad. Sci. USA 94:40864091

16. Deckwerth TL and Johnson Jr EM (1993) Temporal analysis of events associated with programmed cell death (apoptosis) of sympathetic neurons deprived of nerve growth factor (NGF). J. Cell Biol. 123: 1207-1222

17. Edwards SN and Tolkovsky AM (1994) Characterization of apoptosis in cultured rat sympathetic neurons after nerve growth factor withdrawal. J. Cell Biol. 124: $537-546$

18. Estus S, Zaks W, Freeman R, Gruda M, Bravo R and Johnson E (1994) Altered gene expression in neurons during programmed cell death; identification of c-jun as necessary for neuronal apoptosis. J. Cell Biol. 127: 1717-1727

19. Ham J, Babij C, Whitfield J, Pfarr CM, Lallemand D, Yaniv M and Rubin LL (1995) A c-Jun dominant negative mutant protects sympathetic neurons against programmed cell death. Neuron 14: 927-939

20. Deshmukh D, Vasilakos J, Deckwerth TL, Lampe PA, Shivers BD and Johnson EM (1997) Genetic and metabolic status of NGF-deprived sympathetic neurons saved by an inhibitor of ICE-family protease. J. Cell Biol. 135: 1341-1354

21. Martin DP, Schmidt RE, DiStefano PS, Lowry OH, Carter JG and Johnson Jr EM (1988) Inhibitors of protein synthesis and RNA synthesis prevent neuronal death caused by nerve growth factor deprivation. J. Cell Biol. 106: 829-844

22. Abate C, Patel L, Rauscher FJd and Curran T (1990) Redox regulation of fos and jun DNA-binding activity in vitro. Science 249: 1157-1161

23. Kyriakis JM, Banerjee P, Nikolakaki E, Dai T, Rubie EA, Ahmad MF, Avruch J and Woodgett JR (1994) The stress-activated protein kinase subfamily of c-Jun kinases. Nature 369: 1546-1600

24. Kalinich JF, Ramakrishnan N and McClain DE (1997) The antioxidant Trolox enhances the oxidation of $2^{\prime}, 7^{\prime}$-dichlorofluorescin to $2^{\prime}, 7^{\prime}$-dichlorofluorescein. Free Radic. Res. 26: 37-47

25. Jordan J, Ghadge GD, Prehn JH, Toth PT, Roos RP and Miller RJ (1995) Expression of human copper/zinc-superoxide dismutase inhibits the death of rat sympathetic neurons caused by withdrawal of nerve growth factor. Mol. Pharmacol. 47: 1095-1100

26. Park DS, Stefanis L, Yan CYI, Farinelli SE and Greene LA (1996) Ordering the cell death pathway. Differential effects of BCL2, an interleukin-1-converting enzyme family protease inhibitor, and other survival agents on JNK activation in serum/nerve growth factor-deprived PC12 cells. J. Biol. Chem. 271: 21898 21905

27. Tammariello SP, Quinn MT and Estus S (1999) NADPH oxidase contributes directly to oxidative stress and apoptosis in NGF-deprived sympathetic neurons. J. Neurosci. In Press 
28. Bazenet CE, Mota MA and Rubin LL (1998) The small GTP-binding protein Cdc42 is required for nerve growth factor withdrawal-induced neuronal death. Proc. Natl. Acad. Sci. USA 95: 3984-3989

29. Bokoch GM (1995) Regulation of the phagocyte respiratory burst by small GTPbinding proteins. Trends Cell Biol. 5: 109-113

30. Brenner B, Koppenhoefer U, Weinstock C, Linderkamp O, Lang F and Gulbins E (1997) Fas- or ceramide-induced apoptosis is mediated by a Rac1-regulated activation of Jun N-terminal kinase/p38 kinases and GADD153. J. Biol. Chem. 272: 22173-22181

31. Goldkom T, Dressler KA, Muindi J, Radin NS, Mendelsohn J, Menaldino D, Liotta D and Kolesnick RN (1991) Ceramide stimulates epidermal growth factor receptor phosphorylation in A431 human epidermoid carcinoma cells. Evidence that ceramide may mediate sphingosine action. J. Biol. Chem. 266: 1609216097

32. Virdee K, Bannister AJ, Hunt SP and Tolkovsky AM (1997) Comparison between the timing of JNK activation, c-Jun phosphorylation, and onset of death commitment in sympathetic neurones. J. Neurochem. 69: 550-561

33. Eilers A, Whitfield J, Babij C, Rubin LL and Ham J (1998) Role of the Jun kinase pathway in the regulation of c-Jun expression and apoptosis in sympathetic neurons. J. Neurosci. 18: 1713-1724

34. Tammariello SP, Landreth GE and Estus S (1999) The role of Jun kinases in apoptosis. In: M. P. Mattson, S. Estus, \& V. Rangnekar (Eds.), Molecular and Cellular Apoptotic Mechanisms. New York: Humana Press pp. In Press

35. Freeman RS, Estus S and Johnson Jr EM (1994) Analysis of cell cycle-related gene expression in postmitotic neurons: selective induction of cyclin D1 during programmed cell death. Neuron 12: 343-355

36. Heintz N (1993) Cell death and the cell cycle: a relationship between transformation and neurodegeneration? Trends Biochem. Sci. 18: 157-159
37. Griendling KK and Ushio-Fukai M (1998) Redox control of vascular smooth muscle proliferation. J. Lab. Clin. Med. 132: 9-15

38. Migheli A, Cavalla P, Marino S and Schiffer D (1994) A study of apoptosis in normal and pathologic nervous tissue after in situ end-labeling of DNA strand breaks. J. Neuropathol. Exp Neurol. 53: 606-616

39. Lassmann H, Bancher C, Breitschopf $H$, Wegiel J, Bobinski M, Jellinger $K$ and Wisniewski HM (1995) Cell death in Alzheimer's disease evaluated by DNA fragmentation in situ. Acta Neuropathol (Berl) 89: 35-41

40. Anderson AJ, Su JH and Cotman CW (1996) DNA damage and apoptosis in Alzheimer's disease: colocalization with c-Jun immunoreactivity, relationship to brain area, and effect of postmortem delay. J. Neurosci. 16: 1710-1719

41. Goto K, Ishige A, Sekiguchi K, lizuka S, Sugimoto A and Yuzurihara M (1990) Effects of cycloheximide on delayed neuronal death in rat hippocampus. Brain Res. 534: 299-302

42. Linnik MD, Zobrist RH and Hatfield MD (1993) Evidence supporting a role for programmed cell death in focal cerebral ischemia in rats. Stroke 24: 2002-2009

43. MacManus JP, Buchan AM, Hill IE, Rasquinha I and Preston E (1993) Global ischemia can cause DNA fragmentation indicative of apoptosis in rat brain. Neurosci. Lett. 164: 89-92

44. Estus S (1997) Optimization and validation of RT-PCR as a tool to analyze apoptotic gene expression. In: J Poirier (Eds.), NeuroMethods 29: Apoptosis Techniques and Protocols. Totowa, NJ: Humana Press pp. 67-84

45. Estus S, Tucker HM, van Rooyen C, Wright S, Brigham E, Wogulis Mand Rydel R (1997) Aggregated amyloid- $\beta$ protein induces cortical neuronal apoptosis and concomitant 'apoptotic' pattern of gene induction. J. Neurosci. 17: 7736-7745 